\title{
Detection of the 2010 Chilean tsunami using satellite altimetry
}

\author{
B. D. Hamlington ${ }^{1,2}$, R. R. Leben ${ }^{1}$, O. A. Godin ${ }^{2,3}$, J. F. Legeais ${ }^{4}$, E. Gica ${ }^{5,6}$, and V. V. Titov ${ }^{6}$ \\ ${ }^{1}$ Colorado Center for Astrodynamics Research, University of Colorado, Boulder, USA \\ ${ }^{2}$ Cooperative Institute for Research in Environmental Sciences, University of Colorado, Boulder, USA \\ ${ }^{3}$ NOAA/Earth System Research Laboratory, Physical Sciences Division, Boulder, USA \\ ${ }^{4}$ Collecte Localisation Satellites, Space Oceanography Division, Toulouse, France \\ ${ }^{5}$ Joint Institute for the Study of the Atmosphere and Ocean, University of Washington, Seattle, WA, USA \\ ${ }^{6}$ NOAA Center for Tsunami Research, NOAA/PMEL, Seattle, Washington, USA
}

Received: 7 February 2011 - Revised: 9 June 2011 - Accepted: 12 July 2011 - Published: 1 September 2011

\begin{abstract}
Tsunamis are difficult to detect and measure in the open ocean because the wave amplitude is much smaller than it is closer to shore. An effective early warning system, however, must be able to observe an impending tsunami threat far away from the shore in order to provide the necessary lead-time for coastal inhabitants to find safety. Given the expansiveness of the ocean, sensors capable of detecting the tsunami must also have very broad areal coverage. The 2004 Sumatra-Andaman tsunami was definitively detected in the open ocean from both sea surface height and sea surface roughness measurements provided by satellite altimeters. This tsunami, however, was exceptionally strong and questions remain about the ability to use such measurements for the detection of weaker tsunamis. Here we study the 2010 Chilean tsunami and demonstrate the ability to detect the tsunami in the open ocean. Specifically, we analyze the utility of filtering in extracting the tsunami signal from sea surface height measurements, and, through the use of statistical analyses of satellite altimeter observations, we demonstrate that the 2010 Chilean tsunami induced distinct and detectable changes in sea surface roughness. While satellite altimeters do not provide the temporal and spatial coverage necessary to form the basis of an effective early warning system, tsunami-induced changes in sea surface roughness can be detected using orbiting microwave radars and radiometers, which have a broad surface coverage across the satellite ground track.
\end{abstract}

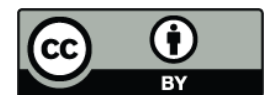

Correspondence to: B. D. Hamlington (hamlingt@ colorado.edu)

\section{Introduction}

An early and dependable assessment of a tsunami threat requires detection of the tsunami in the open ocean away from the shore (Lautenbacher, 2005; Levin and Nosov, 2005; Bernard et al., 2006; Schindele et al., 2008). In the open ocean, however, the tsunami wave amplitude is small (generally much less than one meter) and it is only as it approaches the shore that the tsunami grows in amplitude. Given the expansiveness of the ocean, sensors capable of detecting the tsunami must have very broad areal coverage and must be reliable with few false warnings. If coastal populations go to great lengths to move to safe areas only to find out later such an evacuation was unnecessary, they may be less likely to heed warnings in the future. When used in conjunction with traditional seismic data and point measurements provided by the Deep-ocean Assessment and Reporting of Tsunamis (DART) buoys network (Gonzalez et al., 2005; Bernard et al., 2006), wide-area satellite observations of tsunami manifestations in the ocean can potentially improve the accuracy and timeliness of tsunami forecasts while reducing the probability of false alarms (Walker, 1996; Dudley and Lee, 1998; Godin, 2004; Levin and Nosov, 2005; Synolakis and Bernard, 2006; Geist et al., 2007; Wei et al., 2008; Behrens et al., 2008).

Perhaps the most obvious measurements to use for satellite-based tsunami detection are changes in sea surface height (SSH). On 26 December 2004, the 9.3 magnitude Sumatra-Andaman earthquake generated a large tsunami in the Indian Ocean, resulting in significant loss of life and underscoring the need for a more reliable system for early tsunami detection and warning (Stein and Okal, 2005; Lay

Published by Copernicus Publications on behalf of the European Geosciences Union. 
et al., 2005; Titov et al., 2005). Before this event, observations of tsunamis by satellite altimeters had led to mixed results, with only the 1992 Nicaraguan and 1995 Chilean tsunami tentatively identified in the historical satellite altimeter records (Okal et al., 1999; Zaichenko et al., 2005). The Sumatra-Andaman tsunami was the first to be clearly observed by satellite altimeters, due largely to its intensity and its sizable area of impact. The tsunami was detected by the satellite altimeters TOPEX, Jason-1, Envisat and GEOSAT Follow On (GFO) (Smith et al., 2005) and by tide gauges throughout the Indian Ocean. Various studies have used filtering techniques to aid in the extraction of the tsunami signal from background ocean variability. Gower (2007) subtracted the smoothed average of SSH measured on previous and subsequent cycles to the tsunami cycle over the same pass. Ablain et al. (2006) also demonstrated the utility of filtering with a more sophisticated technique based on ocean variability mapping. Both of these methods rely on measurements taken a significant amount of time after the tsunami has occurred, making them impractical to use in a real-time detection system.

While satellite altimeters were able to adequately detect the 2004 Sumatra-Andaman tsunami, in general, the probability of detecting a tsunami with a satellite altimeter is very low. The satellite must fly over the tsunami wave within a short time of the genesis of the event due to the great tsunami propagation speed (about $800 \mathrm{~km} \mathrm{~h}^{-1}$ in ocean of $5000 \mathrm{~m}$ depth). Furthermore, tsunami signals in the open ocean are usually weak, with the 2004 Sumatra-Andaman tsunami proving to be the exception rather than the rule. Even if a satellite altimeter was to fly over the propagating tsunami, it is likely that the tsunami signal in the open ocean would be too weak to separate from the background ocean variability (Okal et al., 1998; Hamlington et al., 2011). The importance of implementing some type of filtering when detecting tsunamis in SSH measurements becomes paramount.

Although measurements of SSH can provide definitive detection of sufficiently large tsunamis, the spatial coverage and temporal resolution of satellite altimeters are not suitable for forming the basis of a system for the early detection of tsunamis. Satellite altimeters provide measurements only along their ground tracks and generally require on the order of ten days to obtain near-global coverage. The chances are remote of actually observing a tsunami early enough to warn coastal inhabitants (Okal et al., 1998; Hamlington et al., 2011). Of the tsunami manifestations in the deep ocean, variations in sea surface roughness are one of the most promising for detecting tsunamis from space, provided that these effects can be revealed by orbiting active (scatterometers) and passive (radiometers) scanning microwave sensors, which have sampling swaths on the order of hundreds of kilometers normal to the satellite ground track.

Tsunami-induced variations in sea surface roughness in the open ocean were first observed in visible light originating from a tsunami approaching Oahu in 1994 (Walker,
1996; Dudley and Lee, 1998). These variations were termed "tsunami shadows" and have the appearance of darker stripes on the ocean surface along a tsunami front. Formation of the tsunami shadows as areas with a different root mean square (RMS) surface slope have been explained theoretically as a result of the air-sea interaction; specifically tsunami-induced perturbations in the wind velocity close to the ocean surface that are predicted to be much larger than currents in the tsunami wave (Godin, 2003, 2004). Later theoretical studies (Godin, 2005; Troitskaya and Ermakov, 2008) corroborated these conclusions.

The first definitive measurements of the tsunami effect on sea surface height and radar backscattering strength (a measure of sea surface roughness) in the open ocean were obtained from satellite altimeters during passage of the 2004 Sumatra-Andaman tsunami. Godin et al. (2009) used statistical analyses of multiple years of satellite altimeter observations to definitively demonstrate that the Sumatra-Andaman tsunami induced distinctive variations in sea surface roughness. Troitskaya and Ermakov $(2005,2008)$ also studied sea surface roughness measurements taken by Jason-1 during the Sumatra-Andaman tsunami but without a systematic, quantitative comparison to analogous data in the absence of a tsunami.

Questions remain, however, as to whether similar techniques, both in terms of filtering SSH and performing statistical tests on backscattering strength, could be used to detect a weaker tsunami. In February of 2010, a tsunami occurred off the coast of Chile that provided an opportunity to test these analysis techniques. While weaker than the 2004 Sumatra-Andaman tsunami, the 2010 Chilean tsunami was well sampled by satellite altimeters and was sufficiently large enough that one would desire detection in the open ocean for the purposes of early warning. The remainder of this paper is organized as follows. Section 2 provides further details on the 2010 Chilean tsunami and describes the satellite altimeter data utilized in this study. Also in Sect. 2, we outline the filtering techniques and statistical analyses used to identify the tsunami signal in the satellite altimetry data. Section 3 presents the results of our attempts to detect the tsunami and Sect. 4 discusses challenges and difficulties in extracting the tsunami signal from the data. Finally, in Sect. 5 we present conclusions obtained from this work and discuss their implications for early and real-time tsunami detection using satellite altimeters and, more importantly, using orbiting sidelooking radars and scanning microwave radiometers.

\section{Data and methods}

Waves associated with the 2010 Chilean tsunami were definitively detected by several tidal gauges throughout the Pacific Basin and by DART buoy 32412, southwest of Lima, Peru. The $M_{\mathrm{w}}=8.8$ earthquake occurred at 06:34 UTC about $115 \mathrm{~km}$ northeast of the coastal town of Concepcion, Chile. 


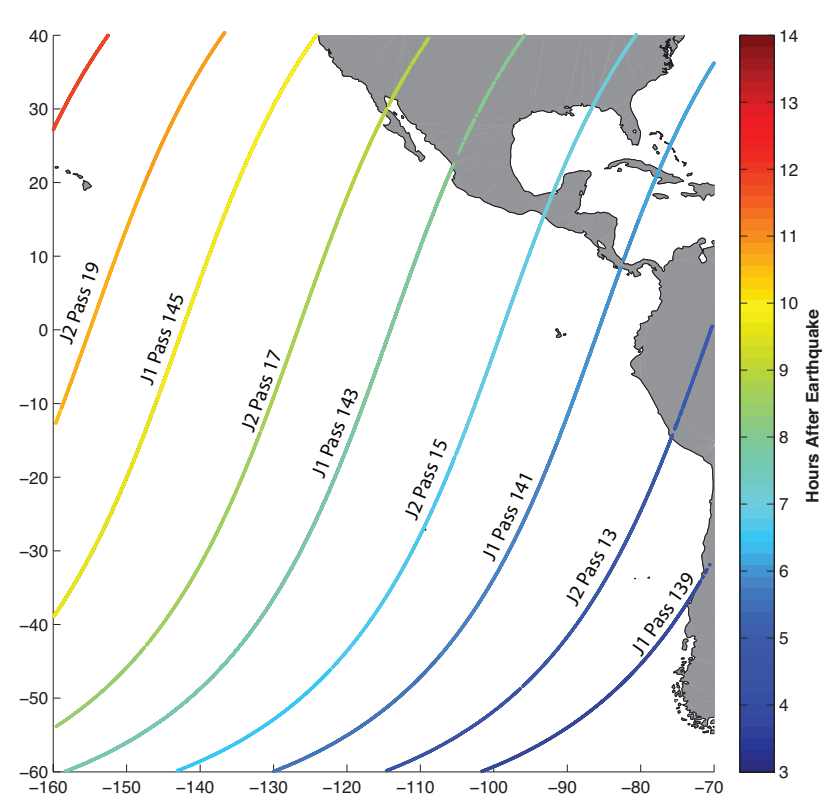

Fig. 1. Jason-1 and Jason-2 passes over the 2010 Chilean tsunami on 27 February 2010.

Estimates of casualties from the tsunami range from 124 to 231 (NOAA NGDC Event Summary, 2010). Although a warning was generated for the entire Pacific region, the tsunami was greatly attenuated by the time it reached locations like Hawaii, New Zealand and Japan. Nevertheless, Japanese fisheries reported damages to aquaculture facilities totaling $¥ 6.26$ billion (Japan Times, 2010) even though the largest wave associated with the tsunami observed in Japan only measured $1.45 \mathrm{~m}$.

\subsection{Satellite altimetry data}

There were multiple satellite altimeters that overflew the tsunami wave field shortly after the tsunamigenic earthquake occurred. Jason-1 sampled the region affected by the tsunami on several passes of cycle 300 . The first ground track to sample the wave field was on ascending pass 139 (Fig. 1) beginning approximately $4 \mathrm{~h}$ after the earthquake. Jason-1 also sampled the tsunami wave field on pass 141 approximately $6 \mathrm{~h}$ after the earthquake, and again on pass 143 approximately $8 \mathrm{~h}$ after the earthquake. Jason- 2 sampled the region affected by the tsunami on ascending pass 11 (Fig. 1) of cycle 61 starting approximately $3 \mathrm{~h}$ after the tsunami occurred The Jason-2 satellite altimeter also sampled the tsunami wave field on ascending passes 13,15 , and 17 at approximate times of 5, 7 and $9 \mathrm{~h}$ after the tsunami generation, respectively. The Envisat satellite altimeter also sampled the region affected by the tsunami, but whereas Jason-1 and Jason-2 sampled the tsunami leading edge at lower latitudes and not long after the tsunami was generated in some passes, Envisat either encountered at the tsunami at very high latitude (in the
Antarctic Circumpolar Current) or long after the tsunami occurred. Significant mesoscale activity is present in the region of the Antarctic Circumpolar Current (Fu and Cazenave, 2001), contributing large amplitude variability to the SSH measurements and decreasing the probability of separating tsunami signals from background ocean variability. We will focus our attention on Jason-1 and Jason-2 due to better sampling of the tsunami and also for the greater ease of detection resulting from the 10-day repeat sampling by these satellites.

Sea surface height measurements were obtained from three separate sources. The satellite altimetry data used in this study was obtained from the Radar Altimeter Database System (RADS). RADS allows the user to quickly search and obtain records from several satellite altimeters (Naeije et al., 2000). All standard satellite altimetry path-length corrections were applied prior to analysis. The altimeter products used for the ocean variability mapping technique have been produced by SSALTO/DUACS and are distributed by AVISO.

Finally, to verify the time and location of the tsunami leading edge, we also used the Method of Tsunami Splitting (MOST) model SSH data produced by the NOAA Center for Tsunami Research (NCTR) (Titov et al., 2005; Titov and Synolakis, 1997) for comparison. The two-dimensional SSH data produced by MOST were interpolated along each altimeter ground-track of interest and compared to the satellite altimetry SSH data. The MOST numerical model (Titov and Gonzalez, 1997) uses non-linear shallow equations to compute the tsunami propagation. The computation uses spherical coordinates taking into account Coriolis force and includes a numerical dispersion scheme to account for the different propagation wave speeds with different frequencies. The computed two-dimensional SSH used by the MOST model is based on a combination from a precomputed tsunami propagation database (Gica et al., 2008). The tsunami propagation database is a database of precomputed tsunamis generated by a pre-defined earthquake source, referred to as a "unit source", where a finite combination can quickly provide offshore forecasts of tsunami amplitudes and other wave parameters. NCTR has developed a pre-computed tsunami propagation database, which consists of 1691 pre-computed model runs, covering along all known faults zones in the Pacific and Atlantic Basins and the Indian Ocean. An elastic deformation model developed by Okada (1985) is used to determine the shape of the earthquake's vertical displacement, which assumes a rupture of a single rectangular fault. Applying a commonly used method, the initial sea surface displacement follows the final ocean bottom displacement generated by the earthquake. The pre-defined "unit source" is based on a typical subduction mechanism with a moment magnitude $\left(M_{\mathrm{w}}\right)$ of 7.5 and based on the asperities of the Aleutian Alaska Subduction Zone (Johnson, 1998); a fault dimension of $100 \mathrm{~km}$ long and $50 \mathrm{~km}$ wide is assigned. Assuming that the earth's rigidity is $4.0 \times 10^{11}$ dynes $\mathrm{cm}^{-2}$, the pre-defined earthquake 
magnitude and fault dimension yields a vertical slip $1 \mathrm{~m}$. The strike angle is assumed to follow the curvature of the subduction zone while the dip angle and depth are based on a study by Kirby et al. (2005). The rake angle has been set to $90^{\circ}$ because this value is most effective in tsunami generation. Titov and Gonzalez (1997) and Gica et al. (2007) conducted sensitivity studies to determine if the variation of an earthquake's fault parameters would cause significant variation in the generated tsunami in the far field. Both studies concluded that the generated tsunami wave is sensitive only to the earthquake's epicenter and magnitude. The pre-defined "unit source" is a source function to generate the initial sea surface displacement. The initial sea surface displacement is further refined once the actual tsunami signals are detected by the DART buoys. When a tsunamigenic earthquake occurs, the appropriate combination of unit sources is automatically selected based on the earthquake magnitude with the slip value distributed evenly among the unit sources. When DART buoys start recording the actual propagating tsunami waves in real-time, the data is ingested into an inversion algorithm (Percival et al., 2010) that will refine the initial sea surface displacement which occurs in the tsunami source region. This method of combining unit sources and refining the tsunami source region based on the recorded tsunami signal was first validated with the 10 June 1996 Andreanov tsunami (Titov and Gonzalez, 1997). Comparison of the first $2.5 \mathrm{~h}$ of tsunami signal between the simulated and recorded tsunami signal showed a good correlation. Validation of this method has been continually done for tsunamigenic events that have occurred since the 1996 Andreanov tsunami and all showed good comparisons. The MOST model was validated for the 27 February 2010 Chilean tsunami where measurements from seismic, GPS and DART buoys were used to infer the earthquake and tsunami sources. Data analysis by comparing the correlation, root mean square and mean absolute error at DART stations and tide gauges showed that the generated initial tsunami source from a fine structure of the earthquake source do not have any significant influence on the modeled tsunami waves (Gica et al., 2010).

\subsection{Extraction of Tsunami signals from SSH}

Two different techniques were used in an attempt to separate the tsunami signal from the background ocean variability in the SSH measurements. The first technique was used by Gower (2007) to identify the SSH signature of the 2004 Sumatra-Andaman tsunami. This method of filtering consists of subtracting a smoothed average (9-s boxcar filter) of SSH measured on the same pass of the cycles before and after the tsunami cycle. While it is possible that SSH differences between the three cycles will introduce some additional error, such filtering should remove the signals resulting from uncorrected geoid heights, mesoscale eddies or ocean currents that persist for time periods longer than the 10-day repeat cycle of Jason-1 and Jason-2. Furthermore, by using only the cycle before the tsunami cycle, we can explore the possibility of using this simple filtering technique for real-time detection of a tsunami signal in SSH measurements. The second, more complex, filtering method is based on a specific mapping technique, first introduced by Ablain et al. (2006). The method involves collecting 20 days of data before and after tsunami occurrence provided by all available altimeters (Jason-1, Jason-2, and Envisat). This window length is chosen to approximately match the decorrelation scale of the mesoscale activity in the region. The data corresponding to the tsunami day is excluded in order to not take into account measurements affected by the tsunami. The ocean variability mapping technique used (Le Traon et al., 1998) provides optimal interpolation in space and time via objective analysis of all the selected data along each altimeter ground track on the day of the tsunami. The resulting interpolated sea level anomaly data correspond to the sea level signals that would have been observed had the tsunami not been present. This interpolated data is subsequently removed from the actual SSH measurements to produce a time series featuring the tsunami signal more prominently and that is approximately unaffected by the background ocean variability. The obtained along-track time series reflects periods lower than approximately 15 days, which is only possible as a result of the good space-time sampling of the ocean obtained with at least three altimeters (Pascual et al., 2006). This method should better extract the signal associated with the tsunami from the background variability since it takes into account not only temporal but also spatial information from other altimeters (Hayashi et al., 2008). This more elaborate technique has been used with success to identify the 2004 Sumatra-Andaman tsunami signal in the satellite altimetry data (Ablain et al., 2006).

Both of these filtering techniques are used in an attempt to extract and identify the tsunami signal resulting from the earthquake occurring on 27 February 2010 off the coast of Chile. The filtered results are also compared to the modeled SSH data produced by MOST and the feasibility of using such methods for real-time detection of tsunamis in the open ocean is considered.

\subsection{Statistical analysis of sea surface roughness variations}

Godin et al. (2009) demonstrated the ability to detect a tsunami in the open ocean through changes in the sea surface roughness for the 2004 Sumatra-Andaman tsunami. This tsunami, however, was an exceptionally large event, and questions remain regarding the utility of sea surface roughness measurements for detecting smaller tsunamis. Satellite altimetry provides concurrent measurements of SSH and radar backscattering strength at nadir, $\sigma_{0}$, which also serves as a measure of sea surface roughness. SSH measurements allow us to identify, in particular, the location of the leading edge of the tsunami, assuming the tsunami 

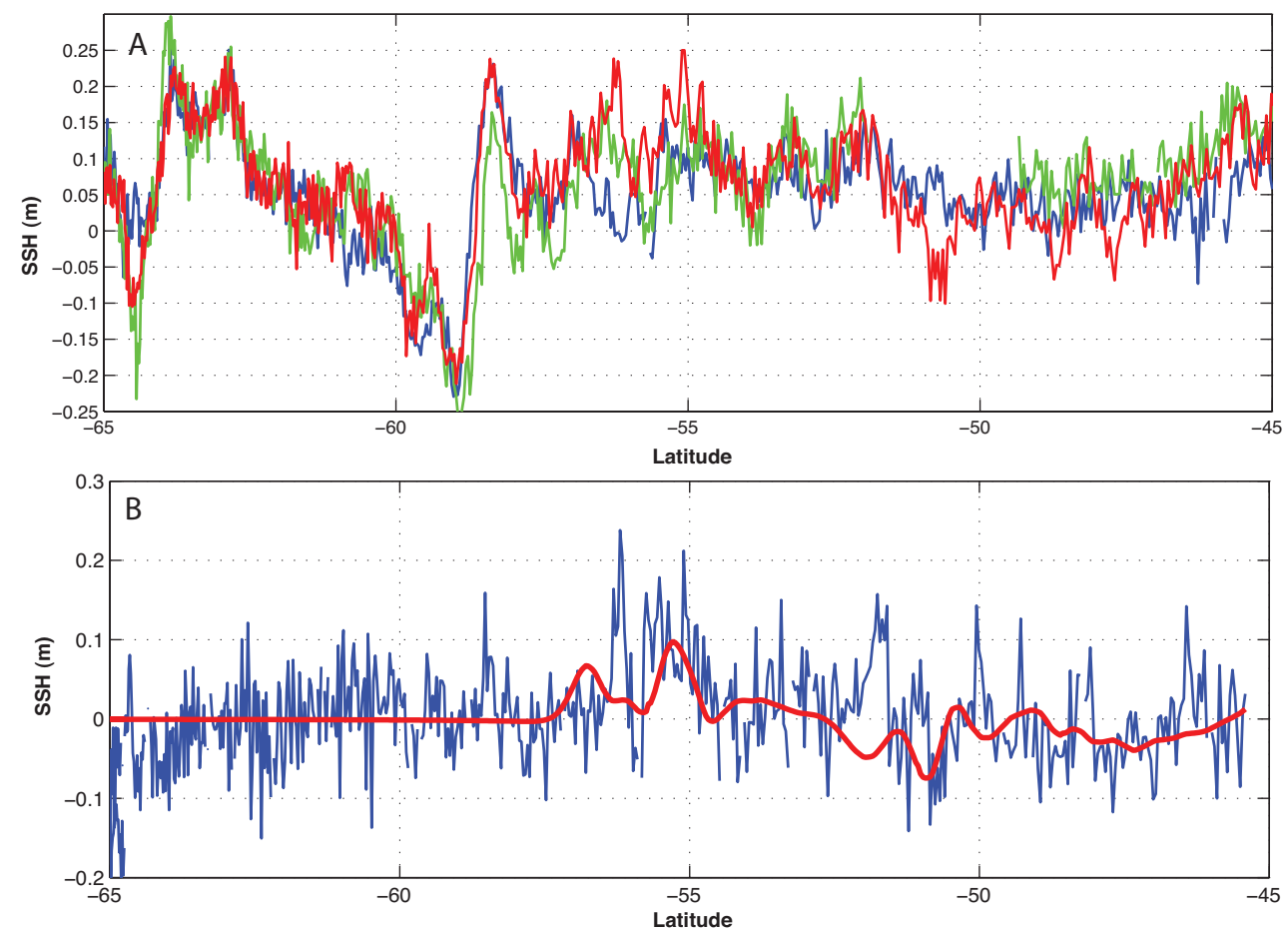

Fig. 2. (A) SSH data for pass 139 of Jason-1 cycles 299 (blue), 300 (red - tsunami) and 301 (green). (B) Filtered SSH data (blue) for pass 139 of cycle 300 with MOST model results (red) overlaid.

signal can be extracted from the background ocean variability. With this information about the leading edge of the tsunami, we can study $\sigma_{0}$ measurements from the satellite altimeter in an attempt to detect tsunami-induced changes in sea surface roughness. Long surface gravity waves in the ocean modulate short gravity and gravity-capillary waves and change ocean surface roughness through the interaction of short waves with near-surface currents and variations of near-surface wind-induced by long waves (Hara and Plant, 1994; Troitskaya, 1994; Kudryavtsev et al., 1997; Godin and Irisov, 2003). Modulation due to currents is negligible for a tsunami in the deep ocean (Godin, 2003, 2004). Tsunamiinduced variations in ocean surface roughness away from the shore result from variations in wind velocity that accompany tsunami waves, and have been predicted to be much larger than currents in the tsunami wave (Godin, 2003, 2004, 2005). Godin $(2003,2004,2005)$ found that significant variations in the mean wind velocity arise from the generation of viscous waves in the atmosphere by coherent large-scale motion of the ocean surface in a tsunami wave. However, the magnitude of the surface roughness modulations and the position of areas with increased and decreased roughness are sensitive to the choice of a closure hypothesis for turbulence in the atmospheric boundary layer. Although any theoretical explanation of tsunami-induced surface roughness variations is still tentative, measuring these variations in the open ocean can provide insight into the physics of the interaction of fast surface waves with turbulent wind.
As outlined in Godin et al. (2009), there is no universally accepted model of airflow over fast sea waves. Using assumptions made in (Godin, 2005), in the presence of a monochromatic tsunami wave, the wind speed relative to the ocean surface retains a logarithmic profile up to a few tens of meters above the surface. The effective wind speed depends on characteristics of the tsunami and differs from the background wind speed by the factor:

$M=1-\frac{\kappa a c}{H u_{*} \ln \beta}$

where $\kappa$ is the von Karman constant, $u_{*}$ is the friction velocity, $H$ is the height of the background logarithmic boundary layer, $a$ is the $\mathrm{SSH}$ change due to the tsunami, $c$ is the tsunami phase speed,

$\beta=\frac{\kappa u_{*} T}{2 \pi z_{0}}$

$z_{0}$ is the roughness length, and $T$ is the tsunami period.

For a monochromatic tsunami wave, the effective wind speed varies periodically in time with the SSH change. As long as the relaxation time of wind waves is much smaller than the tsunami period, the time dependence of the effective wind speed can be disregarded when determining characteristics of the ocean surface roughness that correspond to a given instantaneous value of the wind modulation $M$. Variations in the radar backscattering strength at nadir, $\sigma_{0}$, resulting from the tsunami-induced wind variations can be found 

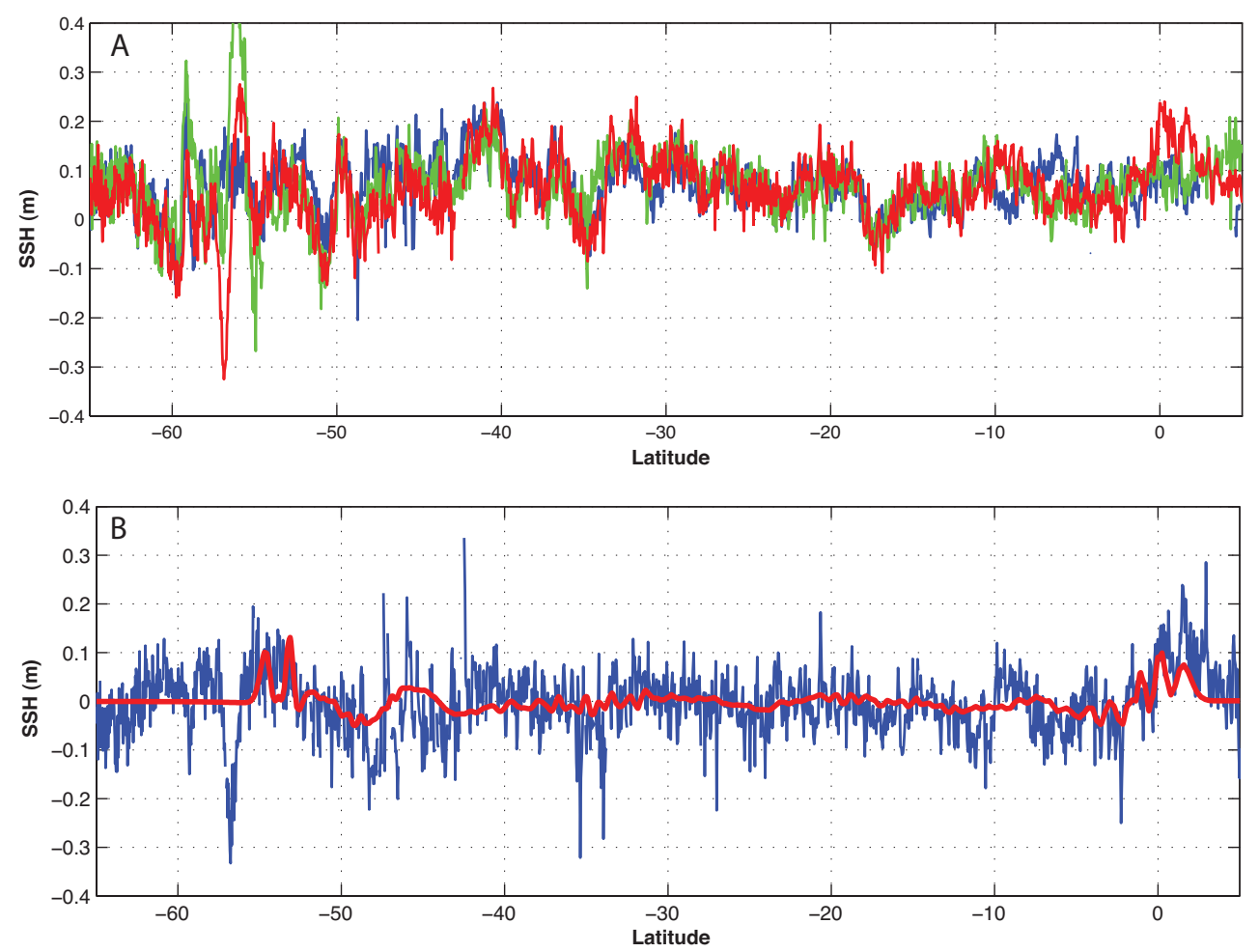

Fig. 3. (A) SSH data for pass 141 of Jason-1 cycles 299 (blue), 300 (red - tsunami) and 301 (green). (B) Filtered SSH data (blue) for pass 141 of cycle 300 with MOST model results (red) overlaid.

in the Modified Chelton-Wentz algorithm (Witter and Chelton, 1991) or the Freilich-Challenor algorithm (Freilich and Challenor, 1994) by comparing the $\sigma_{0}$ values that correspond to the background and effective wind speeds.

Sea surface roughness is influenced by diverse phenomena in the ocean and atmosphere, including wind gusts, currents, internal gravity waves, and oceanographic fronts. The resulting $\sigma_{0}$ variability can far exceed the expected tsunami induced variations. To determine whether the $\sigma_{0}$ variations observed during a tsunami event were indeed caused by a tsunami, data with and without the tsunami present must be compared.

Tsunamis have several distinctive spatio-temporal characteristics that aid in the retrieval of the tsunami signal from the "noise" arising from other geophysical processes. Perhaps the most distinctive attribute of tsunami-induced roughness variations is their propagation speed relative to the ocean bottom. However, satellite altimeters only provide a "snapshot" of the ocean surface, and thus the propagation speed of the tsunami cannot be used to identify tsunami-induced features in satellite altimeter data.

To determine if $\sigma_{0}$ variations were induced by a tsunami, we have performed statistical randomization tests (Edgington, 1995) to compare data with and without the tsunami present. One thousand $3.2^{\circ}$-windows were randomly selected from the area of the ocean through which the tsunami passed. Mean $\sigma_{0}$ values were subtracted in each window to calculate the $\sigma_{0}$ anomaly, and the RMS values and the number of zero crossings were calculated for the $\sigma_{0}$ anomaly in each window. These values were compared to the respective values in the $3.2^{\circ}$-window containing the leading edge of the tsunami. The RMS $\sigma_{0}$ anomaly characterizes the strength of the surface roughness variations, while the number of zero crossings gives a measure of the spatial scale of these variations. If the tsunami-induced variations were distinctive and unique, we would expect the window containing the leading edge of the tsunami to have both a higher RMS and a greater number of zero crossings than found in the 1000 randomly selected windows (Godin et al., 2009; Hamlington et al., 2011).

\section{Results}

\subsection{Observation of 2010 Chilean Tsunami wave in SSH measurements}

As seen in Figs. 1 and 2, the Jason-1 and Jason-2 satellite altimeters both overflew the tsunami wave field multiple times on 27 February 2010. We focus on three passes of each satellite altimeter and apply the filtering techniques introduced in Sect. 2 in an attempt to extract the tsunami signal from the background SSH variability. 

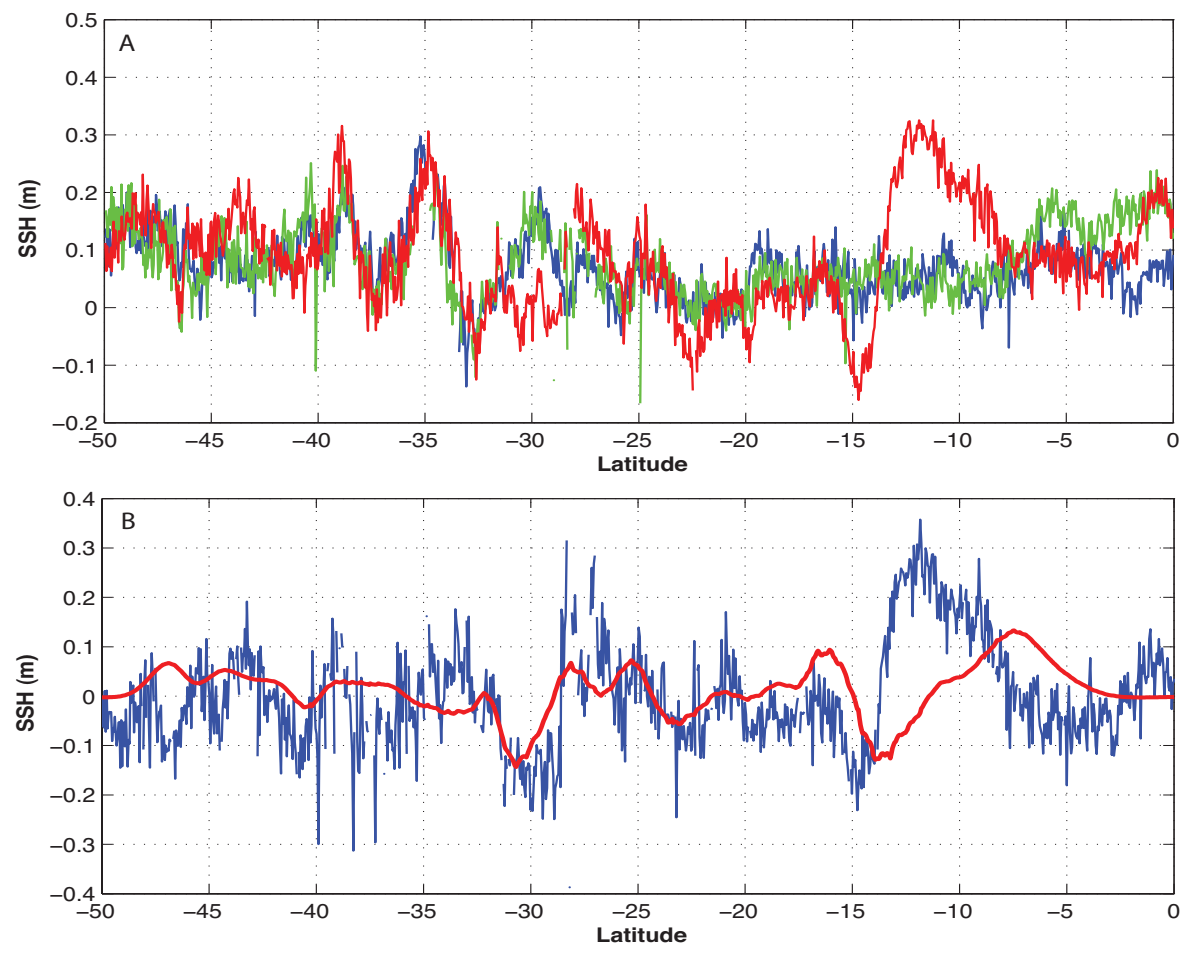

Fig. 4. (A) SSH data for pass 143 of Jason-1 cycles 299 (blue), 300 (red - tsunami) and 301 (green). (B) Filtered SSH data (blue) for pass 143 of cycle 300 with MOST model results (red) overlaid.

\subsubsection{Jason-1}

Jason-1 first sampled the region affected by the tsunami on ascending pass 139 of cycle 300 approximately $4 \mathrm{~h}$ after the tsunami. The top panel of Fig. 2 shows the SSH data for pass 139 on cycles 299 and 301 in addition to the SSH data for the tsunami cycle. While an initial check of the SSH data in cycle 300 suggests the presence of a tsunami-like signal around $58^{\circ} \mathrm{S}$, this signal is also present in the cycles before and after the tsunami. After using the simple filtering based on the cycles immediately before and after the tsunami that was introduced in Sect. 2, the signal around $58^{\circ} \mathrm{S}$ is attenuated and only weaker features remain (Fig. 2b). By sampling the results provided by the MOST model along this pass, we can compare the filtered SSH measurements to the predicted model results. The MOST model suggests that the altimeter should have encountered the leading edge around $57^{\circ} \mathrm{S}$, but this is not decisively confirmed by the satellite altimeter data.

Similar results are obtained when looking at pass 141 of cycle 300 , sampling the tsunami approximately $6 \mathrm{~h}$ after the generation of the tsunami. SSH data for the tsunami cycle and the cycles before and after the tsunami are shown in Fig. 3a. Again, a relatively large signal around $58^{\circ} \mathrm{S}$ is observed, but once the filtering is implemented, this signal is weakened and positive identification of the tsunami cannot be made. Furthermore, comparison to the MOST model data demonstrates only a weak agreement and suggests the pres- ence of wave amplitudes on the order of $10 \mathrm{~cm}$. The more complex filtering introduced by Ablain et al. (2006) has not been shown for these two passes since similarly poor results are obtained and there is no definitive positive identification.

Pass 143 of cycle 300 sampled the tsunami wave field at just less than $8 \mathrm{~h}$ after the tsunamigenic earthquake occurred. A large tsunami-like signal can be seen at $15^{\circ} \mathrm{S}$ in cycle 300 that is not present in the cycles immediately before and after (Fig. 4a). Indeed, once filtering is applied, this feature appears very prominently in the resulting SSH signal with amplitude close to $30 \mathrm{~cm}$. The MOST model suggests a similar location and amplitude for the leading edge of the tsunami signal although with a substantially different wavelength, an aspect of the comparison that will be discussed further in Sect. 4. While the signal seen around $15^{\circ} \mathrm{S}$ appears to arise from the leading edge of the tsunami, it is important to consider the level of background variability in this region relative to the strength of the signal we observe. Following the method of Hayashi (2008), we quantify the level of the background variability in the region of pass 143 using five cycles before and after the tsunami. We obtain an average background noise of $4.7 \mathrm{~cm}$ RMS for pass 143 of Jason1. This noise is estimated by the RMS of the cycle-to-cycle differences evaluated from the 5 cycles before and after the tsunami. In particular, where we identify the leading edge of the tsunami $\left(\sim 15^{\circ} \mathrm{S}\right)$, the background signal is between 


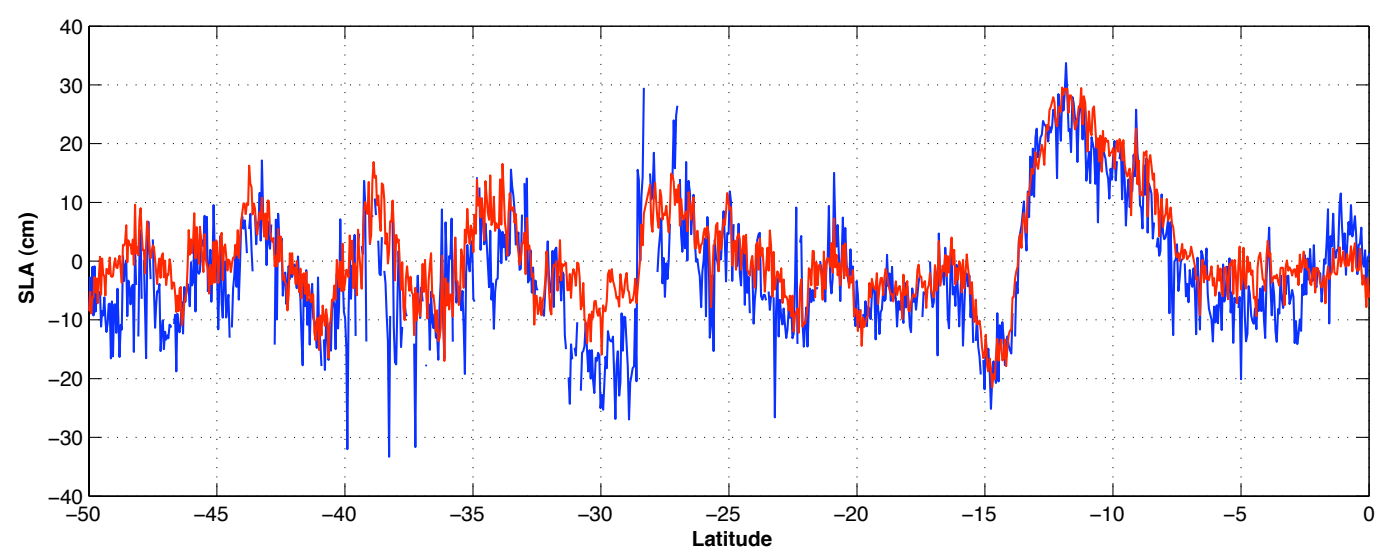

Fig. 5. Filtered SSH for pass 143 of cycle Jason-1 cycle 300 using the Gower (2007) techniue (blue) and the Ablain et al. (2006) technique (red).
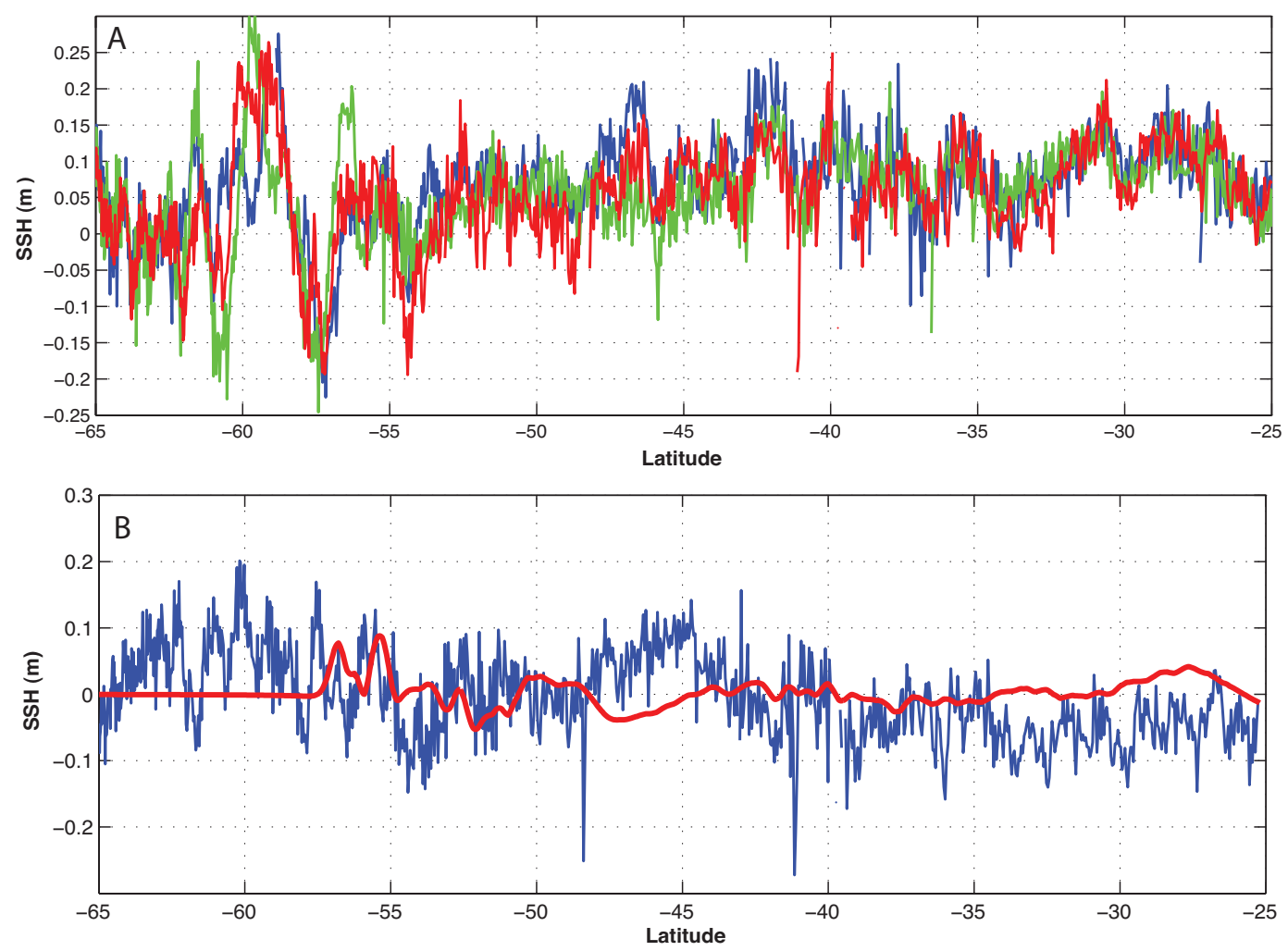

Fig. 6. (A) SSH data for pass 13 of Jason-2 cycles 60 (blue), 61 (red - tsunami) and 62 (green). (B) Filtered SSH data (blue) for pass 13 of cycle 61 with MOST model results (red) overlaid.

$2 \mathrm{~cm}$ and $4 \mathrm{~cm}$ RMS, much lower than the $60 \mathrm{~cm}$ peak-totrough tsunami signal seen in the filtered SSH data. Given the agreement with the MOST model and the strength of the tsunami signal relative to the background variability common to this region, we are confident that the tsunami signal is unambiguously present in pass 143 of Jason-1 cycle 300.

After the positive identification from the simple filtering technique, we applied the mapping technique of Ablain et al. (2006) to determine the results obtained from a more sophisticated filtering technique. Figure 5 shows the comparison between the filtered SSH obtained from the Gower (2007) technique and the filtered SSH obtained from the Ablain et al. (2006) technique. Both techniques capture the significant tsunami signal at $15^{\circ} \mathrm{S}$, implying that positive identification of the tsunami can be made using both techniques. Additionally, as discussed in Hayashi (2008), this 

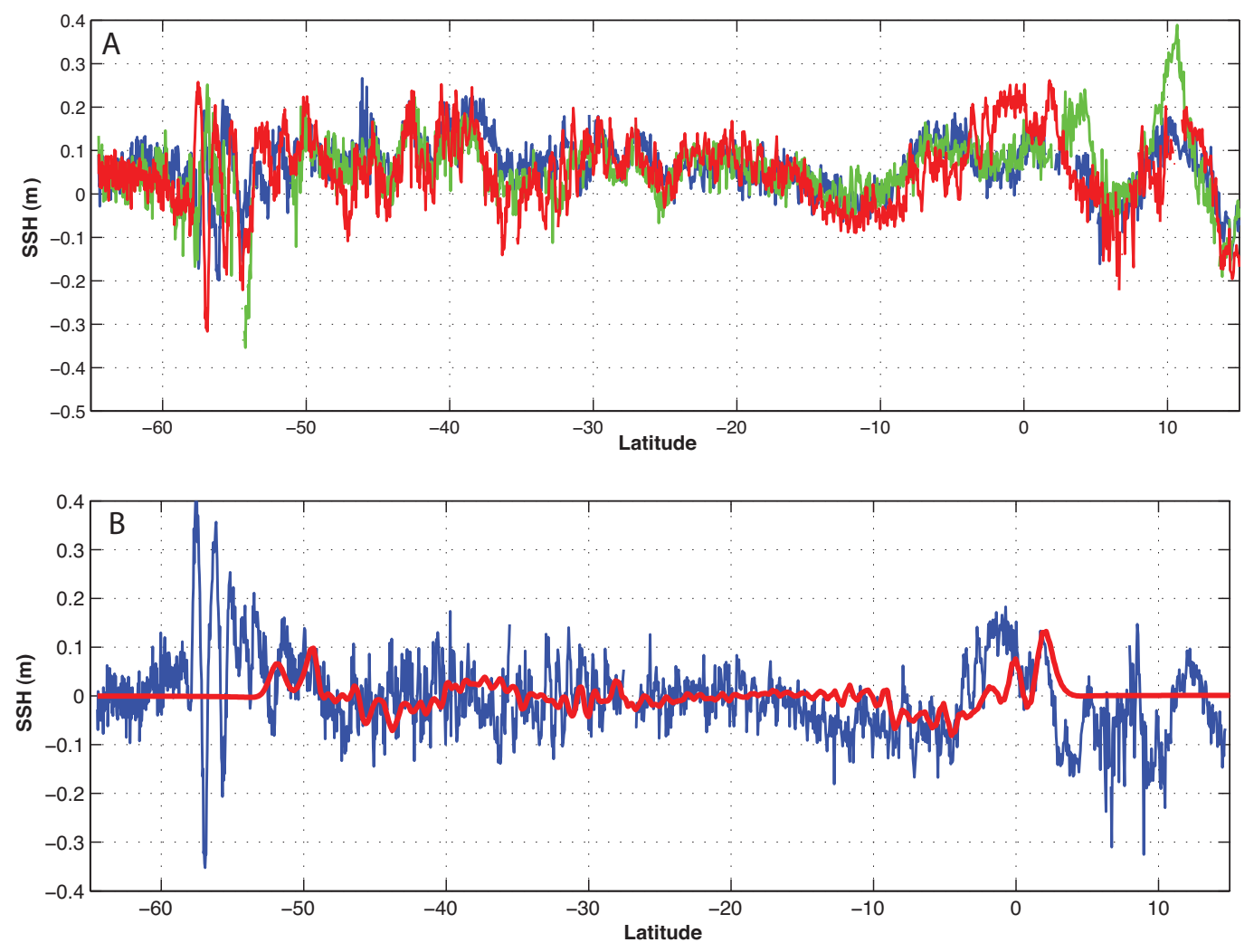

Fig. 7. (A) SSH data for pass 15 of Jason-2 cycles 60 (blue), 61 (red - tsunami) and 62 (green). (B) Filtered SSH data (blue) for pass 15 of cycle 61 with MOST model results (red) overlaid.

more sophisticated filtering should lead to a reduced level of background variability, allowing for even better extraction of the tsunami signal. However, a significant difference in the two filtering techniques is seen near $30^{\circ} \mathrm{S}$. The simpler filtering technique yields a feature with amplitude approaching $20 \mathrm{~cm}$, while the mapping filter technique yields a much weaker signal. The fact that the more sophisticated technique is theoretically able to better remove the ocean variability suggests that this feature is not associated with the tsunami. Regardless, in contrast to passes 139 and 141, the tsunami signal has been unambiguously extracted from pass 143 of Jason-1 cycle 300.

\subsubsection{Jason-2}

The Jason-2 satellite altimeter first encountered the region affected by the tsunami at a high latitude along ascending pass 11 of cycle 61 approximately $3 \mathrm{~h}$ after the tsunami. Due to the limited sampling of the area before reaching the South American coast along pass 11 (Fig. 2), we forego analysis and begin our study on pass 13 , occurring roughly $5 \mathrm{~h}$ after the tsunami was generated. Figure 6a shows the SSH measurements taken along pass 13 of cycles 60, 61 and 62 . Once the filtering is applied, only amplitudes less than $10 \mathrm{~cm}$ are observed after the tsunami arrival (Fig. 6b). The MOST model provides a leading edge location around $57^{\circ} \mathrm{S}$, but it is difficult to ascertain the location of the leading edge from the filtered SSH data due to the low amplitudes of the variations.

Jason-2 also sampled the tsunami wave field on passes 15 and 17 approximately 7 and $9 \mathrm{~h}$, respectively, after the generation of the tsunami. Figure 7a shows the SSH for pass 15 for the tsunami cycle and the cycles immediately before and after. The MOST model results show a leading edge location around $50^{\circ} \mathrm{S}$, but this is not similarly represented in the filtered SSH (Fig. 7b). Additionally, while the filtered SSH data and MOST model data provide similar locations for the leading edge, the amplitudes are much less than $10 \mathrm{~cm}$. Figure 8 shows similar results for pass 17 of Jason- 2 cycle 61 with amplitudes close to $5 \mathrm{~cm}$ but with good agreement between the filtered SSH and MOST model data.

None of the three Jason-2 passes over the tsunami allow for a definitive positive identification of the tsunami wave. While some agreement is seen between the MOST model data and the filtered SSH data in terms of the location of the tsunami leading edge, the amplitude of the tsunami wave at these locations is very small, making it difficult to fully separate the signal from the background noise and ocean variability. Filtering using the Ablain et al. (2006) mapping technique has yielded similarly poor results and will thus not be shown in detail here. 

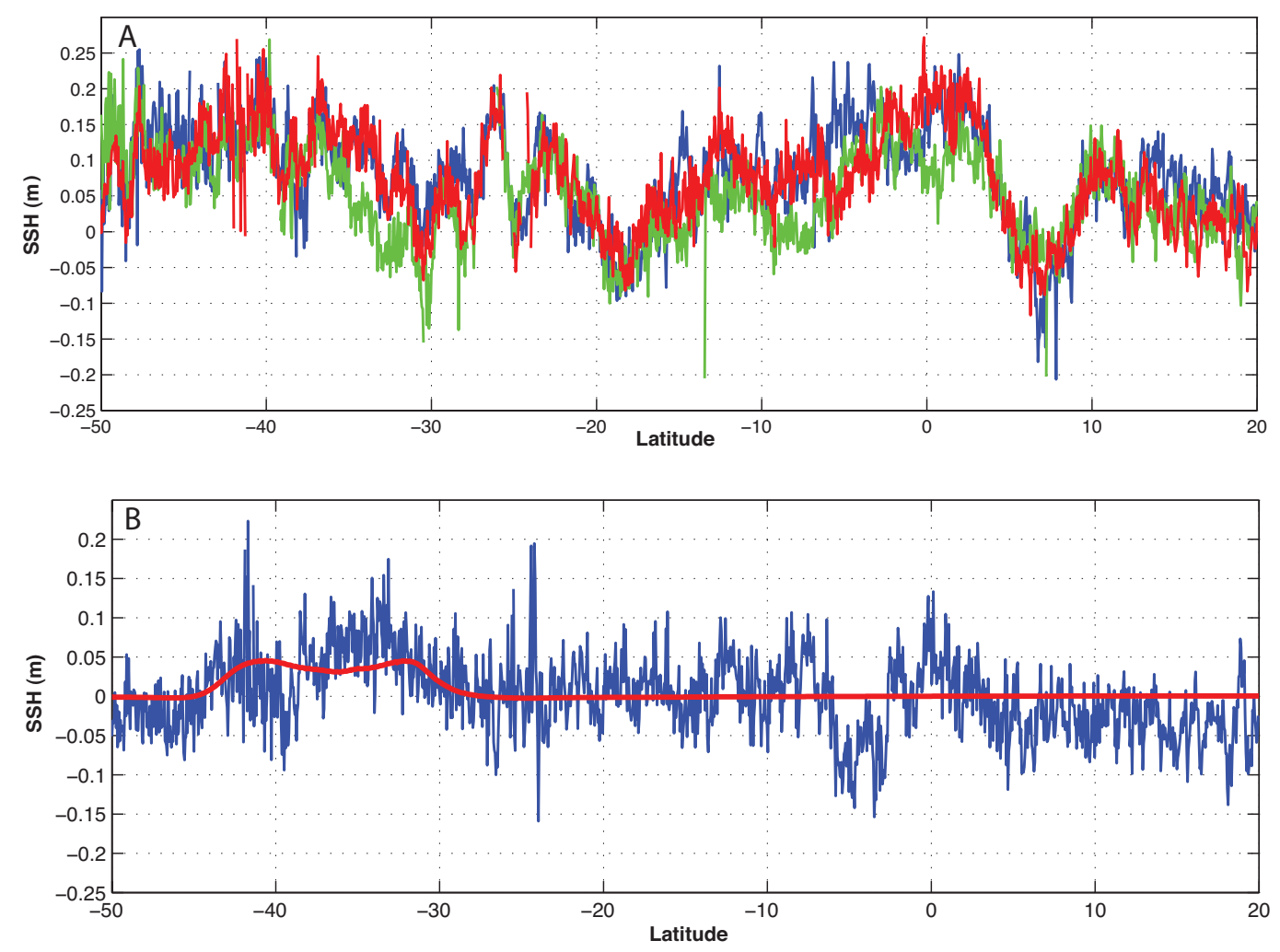

Fig. 8. (A) SSH data for pass 17 of Jason-2 cycles 60 (blue), 61 (red - tsunami) and 62 (green). (B) Filtered SSH data (blue) for pass 17 of cycle 61 with MOST model results (red) overlaid.

\subsection{Observation of 2010 Chilean Tsunami wave in sea surface roughness measurements}

With the positive identification of the tsunami signal in pass 143 of Jason- 1 cycle 300 , a $3.2^{\circ}$-window is selected surrounding the leading front of the tsunami. The window selected is from approximately $16^{\circ} \mathrm{S}$ and $12^{\circ} \mathrm{S}$, with the spatial extent of the segment on the order of the tsunami wavelength. The tsunami is clearly present in this window with amplitude of greater than $20 \mathrm{~cm}$ (Fig. 4). Data quality in the window is high and there are few data points excluded by quality controls. Radar backscattering strengths measured in both the $\mathrm{Ku}$ and $\mathrm{C}$ microwave frequency bands in the vicinity of the leading front of the tsunami do not show variations as strong as those observed for the 2004 Sumatra-Andaman tsunami. This is not surprising or unexpected, however, given the great disparity in the strength of the two tsunamis.

The statistical randomization tests on the sea surface roughness data were conducted by randomly selecting one thousand $3.2^{\circ}$ windows centered between $50^{\circ} \mathrm{S}$ and $10^{\circ} \mathrm{N}$ in the Pacific Ocean from cycles 1-305 of Jason-1. The data was processed as outlined in Sect. 2, and the RMS values and the number of zero crossings were calculated for the $\sigma_{0}$ data in each window. These values were then compared to the respective values in the window covering $15.5^{\circ} \mathrm{S}$ to $12^{\circ} \mathrm{S}$ along pass 143 of cycle 300 . The statistical signifi- cance of the hypothesis that the surface roughness variations with and without the tsunami are not substantially different is $0.7 \%$ and $21.9 \%$ when estimated using the Ku-band and C-band $\sigma_{0}$ data, respectively (Fig. 9). While the randomization test on the Ku-band on the radar backscattering strength yielded positive identification at the $1 \%$ significance level, 30 zero crossings and an RMS $\sigma_{0}$ anomaly of only $0.20 \mathrm{~dB}$ were found for the window containing the leading front of the tsunami. The primary reason for the high significance level is the large number of zero crossings. Given the physical characteristics of the tsunami and the theoretical explanation of the tsunami-induced variations in sea surface roughness, we would expect fewer zero crossings. Using the model described in Sect. 2.3 and Eqs. (1) and (2), the expected $\sigma_{0}$ anomaly RMS values can be theoretically predicted for pass 143 of cycle 300 . With wind speeds between $7-14 \mathrm{~m} \mathrm{~s}^{-1}$ in the region as measured by the Special Sensor Microwave/Imager (SSM/I) instrument on the day of the tsunami, water depths between 3 and $8 \mathrm{~km}$, tsunami wave periods ranging from 30 to 60 minutes, and a tsunami wave amplitude of roughly $0.2 \mathrm{~m}, \sigma_{0}$ anomaly RMS values are theoretically predicted to range between 0.1 and $0.2 \mathrm{~dB}$. This shows excellent agreement with the observed $\sigma_{0}$ anomaly RMS values of $0.20 \mathrm{~dB}$ for the Ku-band and $0.12 \mathrm{~dB}$ for the C-band. 

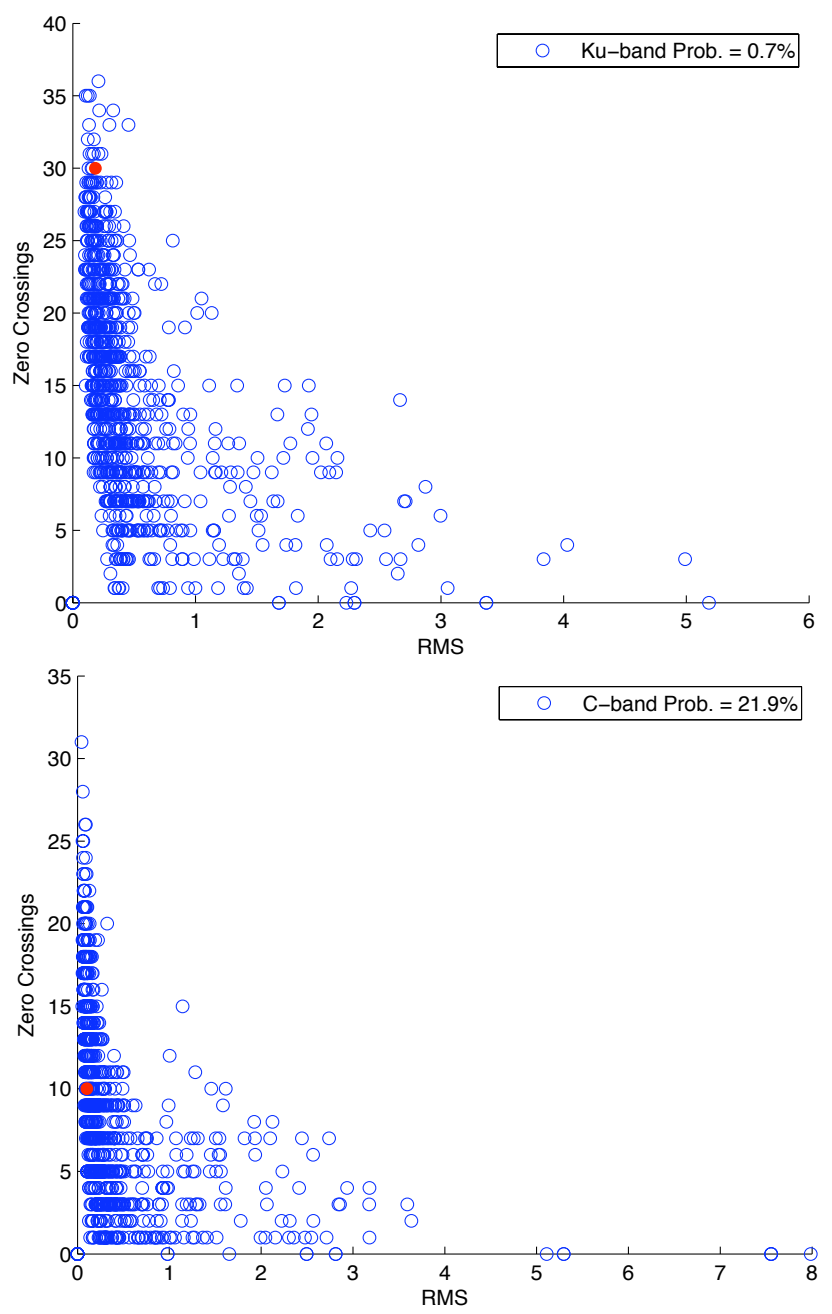

Fig. 9. Results from the statistical randomization tests on the radar backscattering strength for pass 143 of Jason-1 cycle 300. Statistical significance of the hypothesis that surface roughness variations with and without the tsunami are not substantially different is found to be $0.7 \%$ and $21.9 \%$ for the Ku-band and C-band measurements respectively.

The statistical randomization tests conducted suggest that the leading front of the tsunami is detectable in sea surface roughness measurements. In theory, however, the tsunami signal should be detectable at other locations within the tsunami wave field. To test this, we conduct randomization tests using a "sliding window" across the tsunami altimeter pass. In other words, we conduct a randomization test for every $3.2^{\circ}$ window and compute the statistical significance that the surface roughness variations with and without the tsunami are not significantly different. The results of this test are shown in Fig. 10, with the $\mathrm{x}$-axis values representing the center point of each window. Figure 4 shows that the tsunami wave field spans the region from approximately $45^{\circ} \mathrm{S}$ to $5^{\circ} \mathrm{S}$. The statistical significance is generally less than $20 \%$ in this region.
For comparison, the same "sliding window" test can be applied to other altimeter passes in which the leading front of the tsunami was not positively identified in the SSH data. Figure 11 shows the results for pass 141 of Jason-1. The significance level in the region over the estimated tsunami wave field has large variability and is well over $20 \%$ in many locations. Similarly, pass 15 of Jason-2 (Fig. 12) has generally high significance levels over the region of interest. Poor results are also obtained for the other satellite altimeter passes discussed in Sect. 3.1.

\section{Discussion}

To summarize the results above, the SSH signal associated with the 2010 Chilean tsunami has been positively identified in only one satellite altimeter pass, specifically pass 143 of Jason-1 cycle 300 . We have also analyzed two other Jason-1 passes and three Jason-2 passes but were unable to definitively detect the tsunami signal in the filtered SSH data. One reason why we were not able to extract the tsunami from the background variability is the location that the satellite altimeter encountered the tsunami wave. For most of the passes, the satellite altimeter overflew the leading edge of the tsunami at very high latitude $\left(\sim 60^{\circ} \mathrm{S}\right)$ in the Southern Ocean, within the Antarctic Circumpolar Current. Significant mesoscale activity is present in this region (Fu and Cazenave, 2001), contributing large amplitude variability to the SSH measurements and decreasing the probability of observing the tsunami signal in the background ocean variability. Not surprisingly, the only location where the tsunami was unambiguously present and identified in the SSH measurements was near $15^{\circ} \mathrm{S}$.

One way to improve our ability to extract the tsunami signal from the background ocean variability is to filter the data prior to analysis. Gower (2007) and Ablain et al. (2006) used filtering techniques to identify the leading edge of the 2004 Sumatra-Andaman tsunami. These filtering techniques made use of the satellite altimeter measurements before and after the tsunami occurred to remove more persistent signals with longer timescales (temporally with the first method, and both spatially and temporally for the second one) than the tsunami wave. Although the filtering enhanced the tsunami signal relative to the background variability, the Sumatra-Andaman tsunami had significant amplitude even in the open ocean, making it possible to identify without high-pass filtering the data. Attempting to detect a weaker tsunami provides a much more stringent examination of the filtering techniques. The simple technique presented by Gower (2007) shows very close agreement with the more complex filtering of Ablain et al. (2006). Along pass 143 of Jason-1 cycle 300, the satellite altimeter samples the leading edge of the tsunami twice, once between $50^{\circ} \mathrm{S}$ and $30^{\circ} \mathrm{S}$, and then again around $15^{\circ} \mathrm{S}$. A significant difference is observed around $30^{\circ} \mathrm{S}$ between Ablain et al. (2006) and Gower (2007) filtering with an 

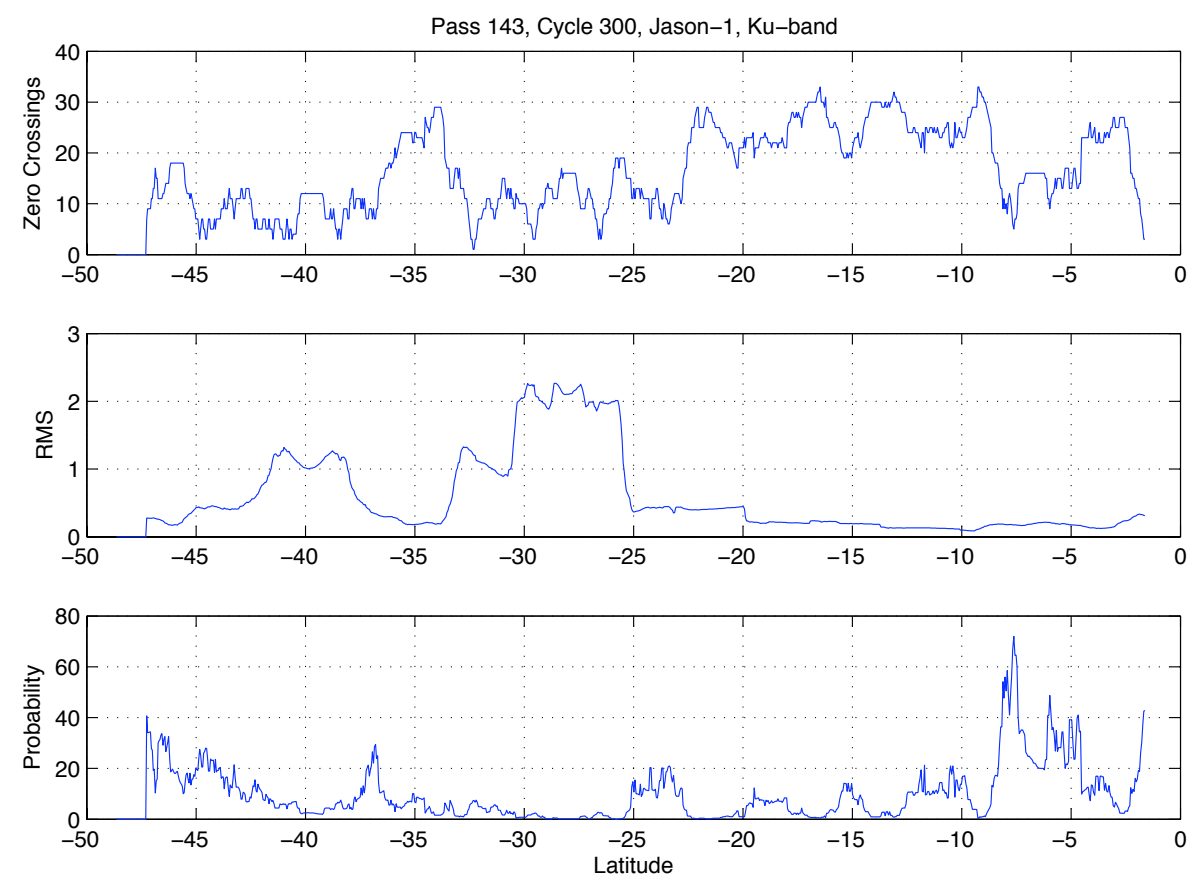

Fig. 10. Statistical randomization tests using a "sliding window" for pass 143 of Jason- 1 cycle 300 . A randomization test is conducted for every $3.2^{\circ}$ window and the statistical significance is computed to test the hypothesis that the surface roughness variations with and without the tsunami present are not significantly different. The $\mathrm{x}$-axis values represent the center point of each window.
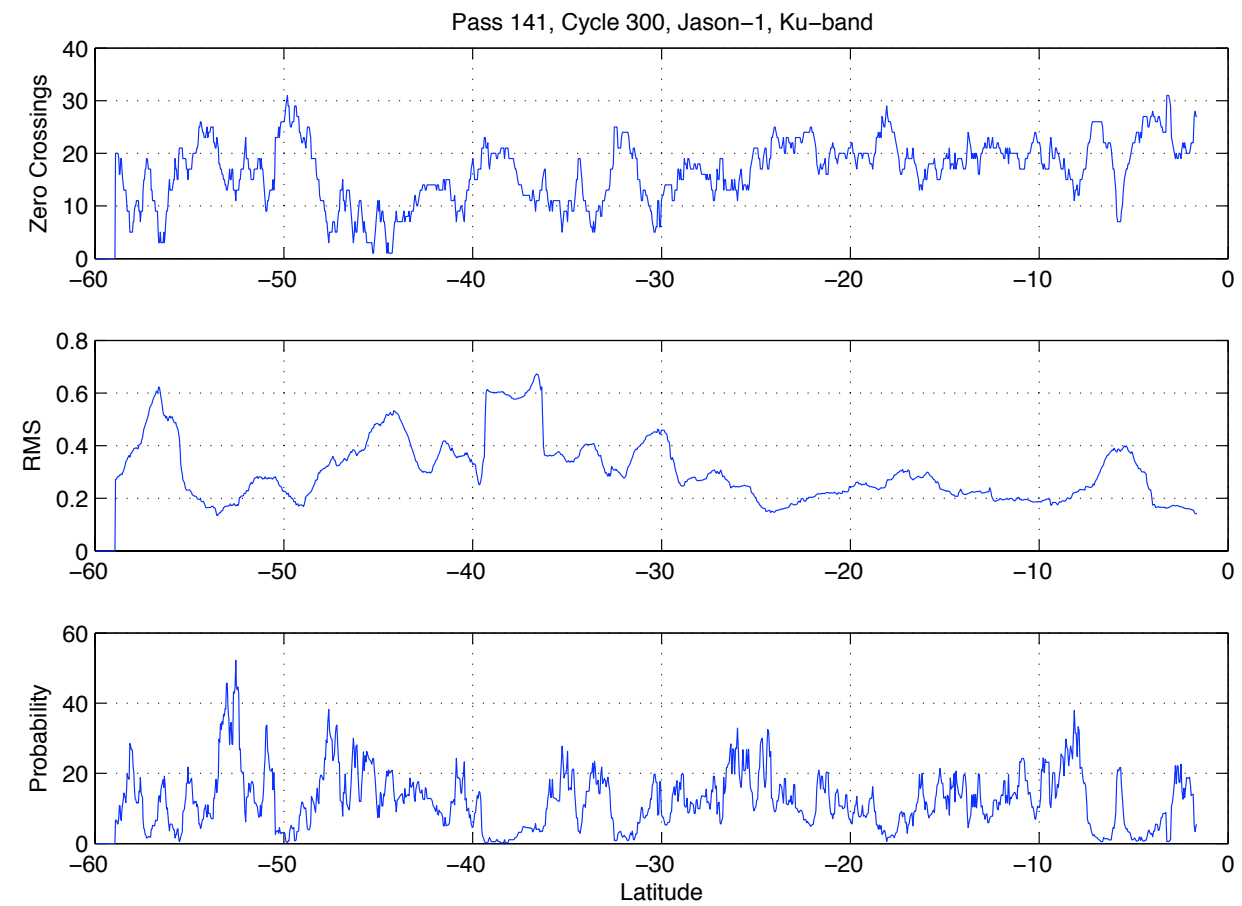

Fig. 11. Statistical randomization tests using a "sliding window" for pass 141 of Jason-1 cycle 300 . A randomization test is conducted for every $3.2^{\circ}$ window and the statistical significance is computed to test the hypothesis that the surface roughness variations with and without the tsunami present are not significantly different. The $\mathrm{x}$-axis values represent the center point of each window. 

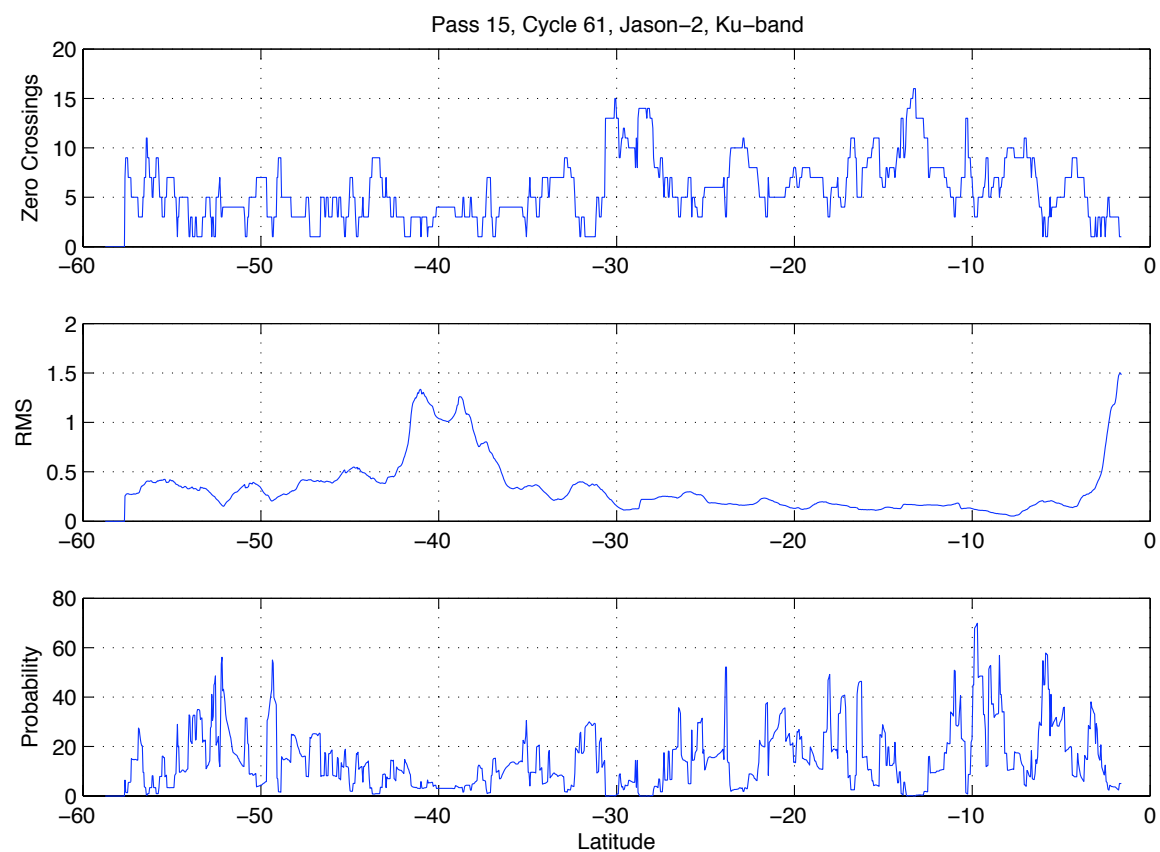

Fig. 12. Statistical randomization tests using a "sliding window" for pass 15 of Jason-2 cycle 61 . A randomization test is conducted for every $3.2^{\circ}$ window and the statistical significance is computed to test the hypothesis that the surface roughness variations with and without the tsunami present are not significantly different. The $\mathrm{x}$-axis values represent the center point of each window.

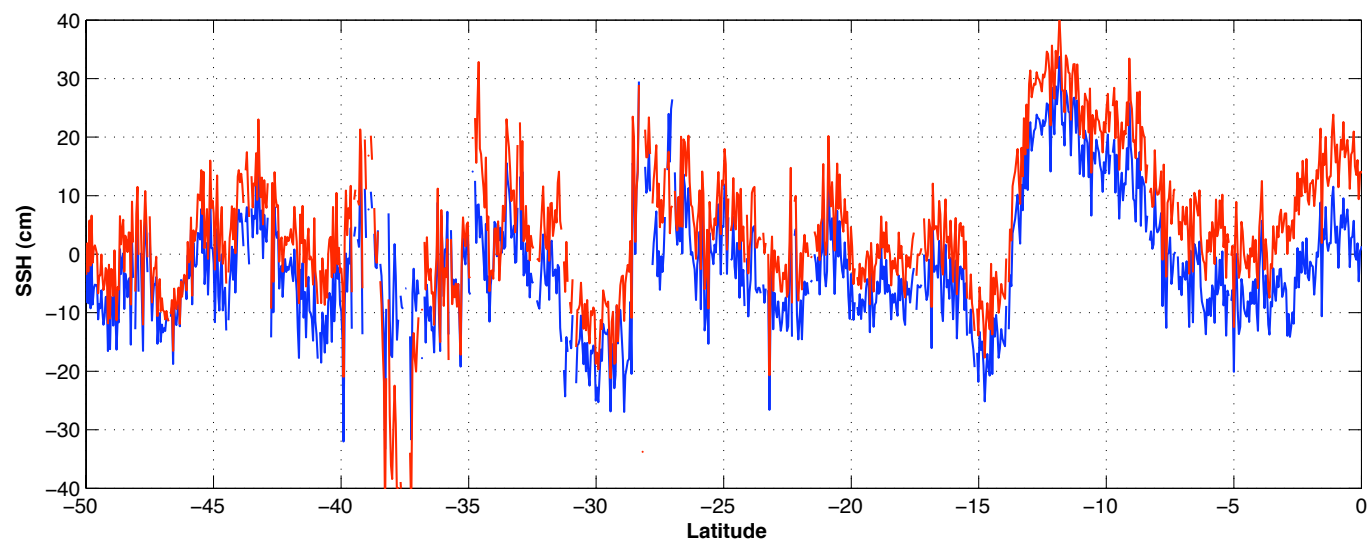

Fig. 13. Filtered SSH for pass 143 of Jason-1 cycle 300 using the Gower (2007) filtering technique. In addition to using the cycles before and after tsunami for filtering (blue), the two cycles before the tsunami cycle are used (red), suggesting that such filtering techniques could be used in real-time.

attenuated amplitude obtained from the more sophisticated filtering technique (Fig. 5). Other differences are also observed between both filtered signals south of $30^{\circ} \mathrm{S}$ with locally peak values $\left(37^{\circ} \mathrm{S}\right.$ and $\left.40^{\circ} \mathrm{S}\right)$ and higher noise $\left(48^{\circ} \mathrm{S}\right)$ obtained with Gower (2007) method. The method of Ablain et al. (2006) filters spatially and temporally and is theoretically able to better remove ocean variability. This suggests that the observed differences (especially at $30^{\circ} \mathrm{S}$ ) are not tsunami-related signals but are ocean variability residuals. Regardless, the good agreement between the results produced by the two filtering techniques suggests that the method proposed by Gower (2007) may be adequate for extracting the tsunami SSH signal from the background variability, at least in the case of significant amplitude of tsunami wave as the one we study.

One significant advantage of the Gower (2007) filtering is the ability to use such a technique in real-time. The Ablain et al. (2006) filtering method requires 20 days of satellite altimetry data both before and after the tsunami occurs. This data is used to map the ocean variability without the tsunami 

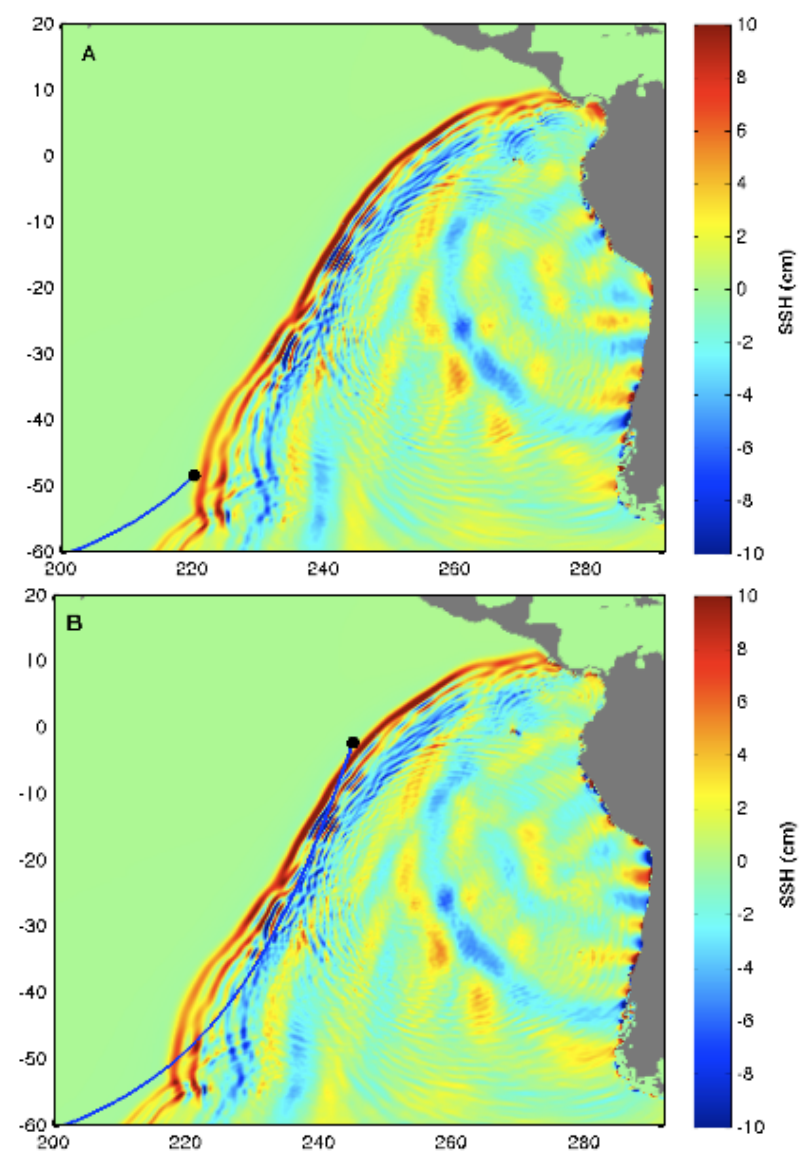

Fig. 14. MOST model results at the time Jason-1 entered the tsunami wave field on pass 143 (according to the model) (A) and at the time Jason-1 departed the tsunami wave field (B). The time between the two images is $\sim 15 \mathrm{~min}$. The oblique sampling of the leading front of the tsunami by Jason-1 provides a possible explanation for the discrepancy between model results and Jason-1 data as seen in Fig. 4.

present, and differencing with the satellite altimeter pass containing the tsunami signal enhances the tsunami signal within the SSH measurements. The Gower (2007) technique, however, only requires the cycle before and after the tsunami to filter the SSH measurements and extract the tsunami signal, and one could easily adjust such a method to only use the data before the tsunami occurs. This would allow the filtering to be applied as soon as a tsunami occurs and satellite altimeter measurements become available. Figure 13 shows the comparison between filtering the SSH measurements from Jason1 pass 143 using the cycles before and after the tsunami cycle and alternatively using a weighted average of the two cycles before the tsunami cycle (cycle immediately before tsunami is given twice the weight of the cycle two cycles prior to the tsunami). The two filtering techniques yield very similar results, implying that the two cycles prior to the tsunami could be used without a great loss of effectiveness, thus allowing for such filtering to be applied in real-time.
In addition to filtering, an important tool for identifying the tsunami signal from the SSH measurements is comparison to the MOST model results. In general, the filtered signals agree well with the MOST model results for the Chilean tsunami and, in particular, from the model results we are able to confirm the location of the leading edge in Jason- 1 pass 143 of cycle 300 near $15^{\circ} \mathrm{S}$. The spatial extent of the leading edge, however, differs significantly between the filtered Jason-1 signal and the results from the MOST model. This is likely a result of the oblique sampling of the tsunami by the Jason-1 satellite altimeter. The Jason-1 ground-track of pass 143 did not enter very far into the tsunami wave field and stayed close to the leading front of the tsunami as the wave propagated across the Pacific Ocean and the altimeter traveled north along pass 143. Figure 14a shows the MOST model results at the approximate time Jason-1 entered the tsunami wave field, while Fig. 14b shows the model results at the time the satellite altimeter departed the tsunami wave field (the time delay between Fig. 14a and b is approximately $15 \mathrm{~min}$ ). As a result of the oblique sampling, a small time difference between reality and the model could result in a considerable change in the estimated location and spatial extent of the leading edge of the tsunami. Furthermore, the ground-track of the altimeter must be taken into consideration when trying to estimate the wavelength of the tsunami. An altimeter traveling perpendicularly to the tsunami wave front would provide a much different estimate of the wavelength when compared to an altimeter moving more tangentially to the tsunami wave front. This underscores some of the difficulties faced in using satellite altimeters for tsunami detection in the open ocean.

By using measurements of the tsunami-induced changes in sea surface roughness, the limitations imposed by the sampling of satellite altimeters can be overcome. Variations in surface roughness can be detected using orbiting active (scatterometers) and passive (radiometers) scanning microwave sensors, which have broad coverage of hundreds of kilometers across the satellite ground track. In addition to having broader coverage across the satellite ground-track and better temporal sampling characteristics, an instrument sampling the tsunami in two dimensions would provide additional benefits to the detection of the tsunami in the open ocean. Spatial averaging of radar backscattering strength along hypothetical tsunami wave fronts could be used to better separate the tsunami signal from the background noise. Furthermore, a series of two-dimensional snapshots of the tsunami wave field would allow tsunami-related features to be distinguished by their uniquely fast propagation speed in the open ocean.

While the 2004 Sumatra-Andaman tsunami was detectable in the open ocean from radar backscattering strength measurements, the tsunami was particularly strong and questions remain about the ability to extract the signal from a weaker tsunami. The extensive satellite altimeter coverage of the 2010 Chilean tsunami provided an opportunity to use the 
statistical randomization tests outlined in Godin et al. (2009) for the detection of the tsunami in the radar backscattering measurements. As seen in section 4, the tsunami was detected with a high degree of certainty in pass 143 of Jason-1 cycle 300 , but the results for other passes were inconclusive. The theoretical expectation for the tsunami-induced variation in sea surface roughness is dependent upon the tsunamiinduced SSH variations. In other words, large SSH variations in the open ocean will lead to large variations of the radar backscattering strength. Thus, it is not surprising that the ability to detect the tsunami in the radar backscattering strength coincided with the highest amplitude SSH observations of the tsunami.

\section{Conclusions}

Satellite altimeters provide the opportunity to study the effects of a tsunami wave in the open ocean not only by providing measurements of the sea surface height, but also through measurements of the sea surface roughness as given by the radar backscattering strength. The SSH data and knowledge of the location of the tsunami leading front allows one to compare statistical properties of the radar backscattering strength when there is and there is not a tsunami present, without having to use tsunami source and propagation models.

Using altimeter observations, we have demonstrated that the 2010 Chilean tsunami can be detected in the open ocean in both SSH and $\sigma_{0}$ measurements. Despite this positive result, it should be noted that even though the Jason-1 and Jason-2 satellite altimeters overflew the tsunami wave field several times, the tsunami was definitively detected in only one pass. With regards to the SSH measurements, this was only after filtering to remove background ocean variability not associated with the tsunami.

The spatial and temporal sampling of satellite altimeters does not allow for their practical implementation as the basis for a tsunami early-detection system operating in the open ocean. Variation of sea surface roughness serves as a more useful tsunami manifestation in the open ocean, and one that could be detected using satellites instruments with much better spatial and temporal sampling. Given the positive identification of the tsunami signal in the $\sigma_{0}$ measurements for the 2004 Sumatra-Andaman tsunami and 2010 Chilean tsunami, such instruments may be an important component in a future global system designed for the early detection and warning of an imminent tsunami threat.

Acknowledgements. This work was supported, in part, by the US Navy under STTR contract N06-T002. The authors thank V. G. Irisov for discussions that greatly improved this manuscript.

Edited by: S. Tinti

Reviewed by: two anonymous referees

\section{References}

Ablain, M., Dorandeu, J., Le Traon, P.-Y., and Sladen A.: High resolution altimetry reveals new characteristics of the December 2004 Indian Ocean tsunami, Geophys. Res. Lett., 33, L21602, doi:10.1029/2006GL027533, 2006.

Behrens, J., Androsov, A., Harig, S., Klaschka, F., Mentrup, L., Pranowo, W. S., Cui, H. Y., Schroter, J., and Hiller, W.: Design and performance testing of a multi-sensor quick assimilation technique for tsunami early warning in the GITEWS simulation system, Geophys. Res. Abstr., 10, EGU2008-A-01878, 2008.

Bernard, E. N., Mofjeld, H. O., Titov, V., Synolakis, C. E., and Gonzalez, F. I.: Tsunami: scientific frontiers, mitigation, forecasting and policy implications, Phil. T. R. Soc. A, 364, 19892007, doi:10.1098/rsta.2006.1809, 2006.

Dudley, W. C. and Lee, M.: Tsunami!, University of Hawaii Press, Honolulu, 5 302-303, 321-322, 1998.

Edgington, E. S.: Randomization Tests, Marcel Dekker, New York, 1995.

Freilich, M. H. and Challenor, P. G.: A new approach for determining fully empirical altimeter wind speed model functions, J. Geophys. Res., 99, 25051-25062, 1995.

Fu, L.-L. and Cazenave, A.: Satellite Altimetry and Earth Sciences: A Handbook of Techniques and Application, Elsevier, New York, USA, Int. Geophys. Ser., 69, 463 pp., 2001.

Geist, E. L., Titov, V. V., Arcas, D., Pollitz, F. F., and Bilek, S. L.: Implications of the 26 December 2004 Sumatra-Andaman earthquake on tsunami forecast and assessment models for great subduction-zone earthquakes, B. Seismol. Soc. Am., 97, 249270, doi:10.1785/0120050619, 2007.

Gica, E., Teng, M. H., Liu, P. L.-F., Titov, V. V., and Zhou, H.: Sensitivity Analysis of Source Parameters for Earthquake Generated Distant Tsunamis, Journal of Waterway, Port, Coast. Ocean Eng., Special Issue, 133(6), 429-441, 2007.

Gica, E., Spillane, M. C., Titov, V. V., Chamberlin, C. D., and Newman, J. C.: Development of the Forecast Propagation Database for NOAA's Short-Term Inundation Forecast for Tsunamis (SIFT), NOAA Technical Memorandum OAR PMEL139, 2008.

Gica, E., Spillane, M. C., and Titov, V. V.: Modeling the 27 February 2010 Chilean Tsunami Using Sources Inferred from Different Data, Abstract G33A-0825 Poster presented at: 2010 Fall Meeting, AGU, San Francisco, California, USA, 13-17 Dec, 2010.

Godin, O. A.: Influence of long gravity waves on wind velocity in the near-water layer and feasibility of early tsunami detection, Dokl. Earth Sci., 391, 841-844, 2003.

Godin, O. A. and Irisov, V. G.: A perturbation model of radiometric manifestations of oceanic currents, Radio Sci., 38, 8070, doi:10.1029/2002RS002642, 2003.

Godin, O. A.: Air-sea interaction and feasibility of tsunami detection in the open ocean, J. Geophys. Res., 109, C05002, doi:10.1029/2003JC002030, 2004.

Godin, O. A.: Wind over fast waves and feasibility of early tsunami detection from space, in: Frontiers of Nonlinear Physics, edited by: Litvak, A., Inst. Appl. Phys., Nizhny Novgorod, 210-215, 2005.

Godin, O. A., Irisov, V. G., Leben, R. R., Hamlington, B. D., and Wick, G. A.: Variations in sea surface roughness induced by the 2004 Sumatra-Andaman tsunami, Nat. Hazards Earth Syst. Sci., 
9, 1135-1147, doi:10.5194/nhess-9-1135-2009, 2009.

Gonzalez, F. I., Bernard, E. N., Meinig, C., Eble, M. C., Mofjeld, H. O., and Stalin, S.: The NTHMP tsunameter network, Nat. Hazards, 35, 25-39, doi:10.1007/s11069-004-2402-4, 2005.

Gower, J.: The 26 December 2004 tsunami measured by satellite altimetry, Int. J. Remote Sens., 28, 2897-2913, doi:10.1080/01431160601094484, 2007.

Hamlington, B. D., Godin, O. A., Irisov, V. G., and Leben, R. R.: Detection of tsunamis from changes in sea surface roughness, Tsunami, Research and Technologies, Intech, Rjeka, Croatia, 2011.

Hara, T. and Plant, W. J.: Hydrodynamic modulation of short wind-wave spectra by long waves and its measurement using microwave backscatter, J. Geophys. Res., 99, 9767-9784, 1994.

Hayashi, Y.: Extracting the 2004 Indian Ocean tsunami signals from sea surface height data observed by satellite altimetry, J. Geophys. Res., 113, C01001, doi:10.1029/2007JC004177, 2008.

Japan Times: "Fisheries took $¥ 6$ billion hit from Chile tsunami”, Japan Times, March 28, 2010, available at: http://search. japantimes.co.jp/cgi-bin/nn20100328b1.html, 2010.

Johnson, J.: Heterogeneous coupling along the Alaskan-Aleutians as inferred from tsunami, seismic, and geodetic inversions, edited by: Dmowska, R., Academic Press, Adv. Geophys., 39, 1-116, 1998.

Kirby, S., Geist, E., Lee, W. H. K., Scholl, D., and Blakely, R.: Tsunami source characterization for Western Pacific subduction zone: A Preliminary report, USGS Tsunami Subduction Zone Working Group, 2005.

Kudryavtsev, V. N., Mastenbroek, C., and Makin, V. K.: Modulation of wind ripples by long surface waves via the air flow: a feedback mechanism, Bound.-Lay. Meteorol., 83, 99-116, 1997.

Lay, T., Kanamori, H., Ammon, C. J., Nettles, M., Ward, S. N., Aster, R. C., Beck, S. L., Bilek, S. L., Brudzinski, M. R., Butler, R., DeShon, H. R., Ekstrom, G., Satake, K., and Sipkin, S.: The Great Sumatra-Andaman Earthquake of 26 December 2004, Science, 308, 1127-1133, doi:10.1126/science.1112250, 2005.

Lautenbacher, C. C.: Tsunami warning systems, The Bridge, 35, 21-25, 2005.

Le Traon, P.-Y., Nadal, F., and Ducet, N.: An improved mapping method of multi-satellite altimeter data, J. Atmos. Oceanic Technol., 15, 522-534, 1998.

Levin, B. W. and Nosov, M. A.: Physics of Tsunamis and Kindred Phenomena, Janus-K, Moscow, 2005.

Naeije, M., Schrama, E., and Scharroo, R.: The Radar Altimeter Database System project RADS. Proc. of the IEEE 2000 Int. Geoscience and Remote Sensing Symp. (IGARSS 2000), Honolulu, HI, IEEE, 487-490, 2000.

Okada, Y.: Surface deformation due to shear and tensile faults in half-space, Bull. Seis. Soc. Am., 75, 1135-1154, 1985.

Okal, E. A., Piatanesi, A., and Heinrich, P.: Tsunami detection by satellite altimetry, J. Geophys. Res., 104, 599-615, 1999.

Pascual, A., Faugère, Y., Larnicol, G., and Le Traon, P. Y.: Improved description of the ocean mesoscale variability by combining four satellite altimeters, Geophys. Res. Lett., 33(2), L02611, doi:10.1029/2005GL024633, 2006.

Percival, D. B., Arcas, D., Denbo, D. W., Eble, M. C., Gica, E., Mofjeld, H. O., Spillane, M. C., Tang, L., and Titov, V. V.: Extraction of tsunami source coefficients via inversion of DART buoy data, Nat. Hazards, 58(1), 567-590, doi:10.1007/s11069-
010-9688-1, 2011.

Schindelé, F., Loevenbruck, A., and Hébert, H.: Strategy to design the sea-level monitoring networks for small tsunamigenic oceanic basins: the Western Mediterranean case, Nat. Hazards Earth Syst. Sci., 8, 1019-1027, doi:10.5194/nhess-8-1019-2008, 2008.

Smith, W. H. F., Scharroo, R., Titov, V. V., Arcas, D., and Arbic, B. K.: Satellite altimeters measure tsunami, Oceanography, 18, 11-13, 2005.

Stein, S. and Okal, E. A.: Speed and size of the Sumatra earthquake, Nature, 434, 581-582, doi:10.1038/434581a, 2005.

Synolakis, C. E. and Bernard, E. N.: Tsunami science before and beyond Boxing Day 2004, Philos. T. Roy. Soc. A., 364, 22312265, doi:10.1098/rsta.2006.1824, 2006.

Synolakis, C. E., Bernard, E. N., Titov, V. V., Konoglu, U., and Gonzalez, F. I.: Validation and verification of tsunami numerical models, Pure Appl. Geophys., 165(11-12), 2197-2228, 2008.

Titov, V., Rabinovich, A. B., Mofjeld, H. O., Thomson, R. E., and Gonzalez, F. I.: The global reach of the 26 December 2004 Sumatra tsunami, Science, 309, 2045-2048, doi:10.1126/science.1114576, 2005.

Titov, V. and Synolakis, C. E.: Extreme inundation flows during the Hokkaido-Nansei-Oki tsunami, Geopshysics Res. Lett., 24(11), 1315-1318, 1997.

Titov, V. V. and Gonzalez, F. I.: Implementation and Testing of the Method of Splitting Tsunami (MOST) Model, NOAA Technical Memorandum ERL PMEL-112, 1997.

Titov, V. V., Mofjeld, H. O., Gonzalez, F. I. and Newman, J. C.: Offshore Forecasting of Hawaiian Tsunamis generated in AlaskanAleutian Subduction Zone, NOAA Technical Memorandum ERL PMEL-114, 1999.

Troitskaya, Y. I.: Modulation of the growth rate of short surface capillary-gravity wind waves by a long wave, J. Fluid Mech., 273, 169-187, 1994.

Troitskaya, Y. I. and Ermakov, S. A.: Recording of the December 26, 2004 tsunami in the open ocean based on variations in radar scattering section, Dokl. Earth Sci., 405A, 1384-1387, 2005.

Troitskaya, Y. I. and Ermakov, S. A.: Manifestations of the Indian Ocean tsunami of 2004 in satellite nadir-viewing radar backscattering variations, Int. J. Remote Sens., 29, 6361-6371, doi:10.1080/01431160802175348, 2008.

Walker, D. A.: Observations of tsunami "shadows": A new technique for assessing tsunami wave heights?, Science of Tsunami Hazards, 14, 3-11, 1996.

Wei, Y., Bernard, E. N., Tang, L., Weiss, R., Titov, V. V., Moore, C., Spillane, M., Hopkins, M., and Kanoglu, U.: Realtime experimental forecast of the Peruvian tsunami of August 2007 for US coastlines, Geophys. Res. Lett., 35, L04609, doi:10.1029/2007GL032250, 2008.

Zaichenko, M. Y., Kulikov, E. A., Levin, B. V., and Medvedev, P. P.: On the possibility of registration of tsunami waves in the open ocean with the use of a satellite altimeter, Oceanology, 45, 194201, 2005.

Witter, D. L. and Chelton, D. B.: A geosat altimeter wind speed algorithm and a method for altimeter wind speed algorithm development, J. Geophys. Res., 96, 8853-8860, 1999. 